\title{
O PODER EM BOURDIEU E FOUCAULT: CONSIDERAÇÕES SOBRE O PODER SIMBÓLICO E O PODER DISCIPLINAR ${ }^{1}$
}

\author{
POWER IN BOURDIEU AND FOUCAULT: CONSIDERATIONS ABOUT SYMBOLIC \\ POWER AND DISCIPLINARY POWER
}

Tiago Barros ROSA ${ }^{2}$

RESUMO: Este artigo tem como objetivo apresentar algumas das concepções acerca do poder presentes no pensamento de dois clássicos contemporâneos das Ciências Sociais: Pierre Bourdieu (1930-2002) e Michel Foucault (1926-1984). Mais especificamente, analisaremos os fundamentos das noções de poder simbólico e de poder disciplinar, desenvolvidos, respectivamente, em suas obras. A despeito das diferenças teóricas e metodológicas existentes entre os citados autores, intentamos aproximar as distintas noções de poder em seus projetos científicos e contrapô-las à corrente dominante atualmente, cujos pressupostos fundamentais alicerçam-se na teoria weberiana. A ideia de imposição da vontade, tal qual exposta na clássica formulação de poder por Weber, traz em si mesma, indelevelmente, a consciência, o cálculo e a intencionalidade por parte dos atores sociais. Em Foucault e Bourdieu, os indivíduos - sujeitos e agentes sociais - são condicionados e constrangidos por relações e forças exteriores, as quais, muitas vezes, sequer são conscientemente percebidas.

PALAVRAS-CHAVE: Sociologia contemporânea. Relações de poder. Poder simbólico. Poder disciplinar.

ABSTRACT: This article aims to present some of conceptions about power, which are present in the thoughts of two contemporary classics from Social Science: Pierre Bourdieu and Michel Foucault. Most specifically, we will analyze the foundations of the notions of symbolic power and disciplinary power, developed, respectively, on their work. Despite the theoretical and methodological differences in both authors, we attend to approach the distinct notions of power in their scientific projects and to confront them to the currently dominant tendency, whose fundamental assumption are supported by the Weberian theory. The idea of imposition of will, as discussed in Weber's classic formulation of power, brings in itself, indelibly, the awareness, calculation and intentionality by the social actors. Both Foucault and Bordieu, the individuals - subjects and social agents - are conditioned and constrained by external relation and forces, which are often not consciously perceived.

KEYWORDS: Contemporary sociology. Power relations. Symbolic power. Disciplinary power.

\footnotetext{
${ }^{1} \mathrm{O}$ artigo é resultado de discussões das obras de Pierre Bourdieu e Michael Foucault realizadas no NESPOMFCLAR (Núcleo de Estudos e Pesquisa sobre Poder, Organização e Mercado), liderado pela professora Maria Chaves Jardim.

${ }^{2}$ Universidade Estadual Paulista (Unesp), Faculdade de Ciências e Letras, Araraquara - SP - Brasil. Graduando em Ciências Sociais. E-mail: tiagobor2013@gmail.com.
} 


\section{Introdução}

Este artigo tem como objetivo apresentar algumas das concepções acerca do poder presentes no pensamento de dois clássicos contemporâneos das Ciências Sociais: Pierre Bourdieu e Michel Foucault. Buscaremos expor as ideias e singularidades das definições de poder formuladas por ambos os autores, mais especificamente, das noções de poder simbólico em Bourdieu (1989) e de poder disciplinar em Foucault (2011).

Admitindo a existência de diferenças teóricas e metodológicas entre ambos, tentaremos aproximar, sob a insígnia de poder estrutural (PERISSINOTTO, 2007), as distintas concepções de poder no interior de seus projetos científicos.

Como ponto de partida iremos retomar, de maneira sucinta e esquemática, o conceito de poder atualmente hegemônico no campo da Ciência Política, formulado por Max Weber (1984). Nossa intenção, além do fato de os autores dialogarem direta ou indiretamente com Weber, é contrastar os pressupostos fundamentais que distinguem a corrente de pensamento filiada ao autor alemão de finais do século XIX e princípios do século XX, dos franceses, que se destacaram, principalmente, após a década de 1960.

O presente artigo, portanto, é composto, além desta introdução e das considerações finais, de quatro partes: em um primeiro momento trataremos do poder como entendido pela tradição clássica da ciência política, cujo principal expoente é Weber. Logo após, faremos as considerações acerca do poder simbólico em Bourdieu. Em seguida, veremos as proposições de Foucault sobre o que denominou poder disciplinar. Posteriormente, operaremos a aproximação entre os conceitos de Bourdieu e Foucault entendendo-os como poder estrutural.

\section{O Poder na Tradição Clássica}

O poder é comumente compreendido como a capacidade de um determinado indivíduo de impor sua vontade a outros. No que tange à história do pensamento social, filosófico e político muito se teorizou - e se teoriza - acerca do poder. Durante séculos distintas escolas e tradições dedicaram-se a analisá-lo e explicá-lo. Nesta seção descreveremos, de modo bastante esquemático (o que implica uma consciente redução de sua complexidade), a definição de poder que se tornou hegemônica no campo da ciência política, a saber, a formulada pelo sociólogo alemão Max Weber.

Referendando a concepção de poder Weberiana, a tradição clássica do pensamento político retoma a idealização que Thomas Hobbes, no século XVII, faz do Estado, como 
produto da abdicação do poder ilimitado de cada homem - no estado de natureza (guerra de todos contra todos) - em favor de um pacto social buscando a autopreservação e a paz mútua. Tal pacto ou contrato visa ceder o monopólio do poder a um soberano - o Estado.

Sob esta perspectiva, o poder tem uma dimensão, eminentemente, coercitiva, sendo a violência física um instrumento comum, e o Estado, detentor exclusivo de tal prerrogativa.

Já no século XX, Weber explicita sua definição de poder: “[...] poder significa a probabilidade de impor a própria vontade dentro de uma relação social, mesmo que contra toda a resistência e qualquer que seja o fundamento dessa probabilidade." (WEBER, 1984, p. 43).

A ideia de imposição da vontade, pressuposto essencial da concepção Weberiana, contém em sua formulação a intencionalidade e o cálculo por parte dos dominantes e dos dominados. Ela consiste em poder afetar o comportamento de outrem da maneira desejada. $\mathrm{O}$ êxito para o detentor de poder depende, portanto, do comportamento do outro, devendo, por exemplo, o sujeito A deter os meios que induzam no sujeito B o comportamento esperado.

$\mathrm{Na}$ relação de poder, tal qual é tradicionalmente formulada, tanto o agente que pretende exercê-lo quanto o que a ele se submete, realizam cálculos em que visam maximizar suas vantagens. A ideia por detrás de sua operacionalização é que não há nada estrutural ou oculto nas relações de poder. Elas se dariam entre atores conscientes e em relação a assuntos determinados, de maneira episódica (PERISSINOTTO, 2007).

Vemos assim, que é a essa capacidade de disposição sobre os meios que permitem influenciar a vontade de outrem que Weber denomina poder. Podemos imaginar, a partir dessas formulações, "[...] um determinado sujeito contrariado, forçado por meio de ameaças a fazer aquilo que de outro modo não faria [...]", portanto, com plena consciência da sua condição de dominado (PERISSINOTTO, 2007, p. 317). A concepção sobre o poder presente no pensamento dos dois autores que veremos a seguir privilegia em suas formulações pressupostos completamente distintos.

\section{O Poder (Simbólico) em Bourdieu}

A questão concernente à dominação - entendida como a manutenção de uma ordem injusta, que privilegia alguns grupos ou indivíduos em detrimento de outros - encontra-se no âmago do projeto científico de Pierre Bourdieu. O autor diz jamais ter deixado de se espantar com: 
[...] o fato de que a ordem do mundo, tal como está, com seus sentidos únicos e seus sentidos proibidos, em sentido próprio ou figurado, suas obrigações e suas sanções seja grosso modo respeitada, que não haja um maior número de transgressões ou subversões, delitos e 'loucuras'. [...] que a ordem estabelecida, com suas relações de dominação, seus direitos e suas imunidades, seus privilégios e suas injustiças salvo uns poucos acidentes históricos, perpetue-se apesar de tudo tão facilmente, e que condições de existência das mais intoleráveis possam permanentemente ser vistas como aceitáveis ou até mesmo como naturais. (BOURDIEU, 2002, p. 10).

A eternização do arbitrário decorre, segundo Bourdieu (2002, não paginado), da violência simbólica: uma “[...] violência suave, insensível, invisível a suas próprias vítimas, que se exerce essencialmente pelas vias puramente simbólicas da comunicação e do conhecimento, ou, mais precisamente do desconhecimento."

Desse modo, o poder simbólico para Bourdieu (1989) é, fundamentalmente, um poder de construção da realidade. Tal poder detém os meios de afirmar o sentido imediato do mundo, instituindo valores, classificações (hierarquia) e conceitos que se apresentam aos agentes como espontâneos, naturais e desinteressados.

O poder simbólico "faz ver e faz crer", transforma a visão e a ação dos agentes sociais sobre o mundo - e desse modo, o mundo. É um poder “" [...] quase mágico que permite obter o equivalente daquilo que é obtido pela força (física ou econômica) e só se exerce se for reconhecido, quer dizer, ignorado como arbitrário [...]” (BOURDIEU, 1989, p.14).

É necessário saber descobri-lo onde ele se deixa ver menos, onde ele é mais completamente ignorado, portanto, reconhecido: o poder simbólico é, com efeito, esse poder invisível o qual só pode ser exercido com a cumplicidade daqueles que não querem saber que lhe estão sujeitos ou mesmo que o exercem. (BOURDIEU, 1989, p. 7-8).

Segundo Loic Wacquant (2013, p. 89) (considerado um dos maiores herdeiros intelectuais de Bourdieu), “[...] é a luta, e não a reprodução, que se situa no epicentro de seu pensamento e se revela o motor ubíquo tanto da ruptura quanto da continuidade social." Wacquant rechaça o reducionismo de algumas apropriações incidentais da obra de Bourdieu, que tendem a rotulá-lo como reprodutivista, em sua perspectiva, a sociologia de Bourdieu admite as condições para revoluções simbólicas, embora, dentro de um campo restrito de possibilidades, que Bourdieu e Passeron (2014) intitulam campo dos possíveis.

Sendo assim, sob este prisma, vemos diferentes classes e frações de classes envolvidas em uma luta simbólica para impor a definição do mundo social mais conforme aos seus interesses. Os atores sociais se lançam em uma competição contínua visando à aquisição e o controle de diversas espécies de poder ou capital. Bourdieu chama atenção para os atos dos agentes em suas disputas, ressaltando que tais agentes estão desigualmente preparados e 
armados para esta contenda, sendo a própria classe à qual pertencem fonte de consciência (valores, ideias, moral) e conduta (ação).

Um conceito basilar nos pressupostos teórico-metodológicos de Pierre Bourdieu essencial para a compreensão de como se dá e se mantém a dominação entre as classes - é o de habitus. Habitus para Bourdieu diz respeito às disposições adquiridas, principalmente, inconscientemente, que exprimem, entre outros, o gosto pessoal, entendido como julgamentos classificatórios baseados em uma hierarquia de valores, e que geram as práticas dos sujeitos sociais. Habitus é um "[...] princípio gerador de práticas objetivamente classificáveis e, ao mesmo tempo, sistema de classificação (principium divisionis) de tais práticas." (BOURDIEU, 2006, p. 162).

O autor afirma que as condições de participação social (existência no mundo) baseiam-se na herança social, ou seja, nos capitais herdados e adquiridos de acordo com a fração de classe à qual se pertence, e que os indivíduos trazem inscritos nas estruturas do pensamento e no corpo (in-corporado) o acumulado desses capitais.

O sociólogo expande a definição de capital - até então restrita ao capital econômico formulando uma noção de capitais, que ao invés de encontrarem-se objetivados na forma de posses materiais, encontram-se incorporados, isto é, tomando literalmente corpo e condicionando a maneira de ver e ser dos sujeitos; são os capitais sociais e culturais incorporados conscientemente, mas também, de maneira inconsciente.

A classe dominante, cujo poder alicerça-se principalmente no capital econômico, é a vencedora de uma luta pela "hierarquia dos princípios de hierarquização", impondo seus valores tanto através de sua própria produção simbólica quanto por intermédio dos ideólogos conservadores (alguns artistas, jornalistas, intelectuais, etc.) que servem aos interesses dominantes.

Bourdieu (1989) desvela as atividades e os mecanismos mediante os quais as construções mentais cristalizam-se em realidades históricas concretas e apreensíveis sejam enquanto instituições ou enquanto conjuntos de disposições pessoais, isto é, referentes à construção da subjetividade dos indivíduos.

O autor critica algumas tradições de pensamento que reduzem as relações de força a relações de comunicação - caso, por excelência, da antropologia levi-straussiana, herdeira, nesse sentido, da tradição iniciada em Kant e que passando por Durkheim tende a considerar os sistemas simbólicos, como a arte e a linguagem, como instrumentos de comunicação, menosprezando seu caráter impositivo (BOURDIEU, 2007). Para o sociólogo francês, as 
relações de comunicação são sempre relações de poder onde os agentes envolvidos visam aumentar o seu poder simbólico.

\begin{abstract}
Os sistemas simbólicos são instrumentos estruturados e estruturantes de comunicação e de conhecimento que cumprem a sua função política de instrumentos de imposição ou de legitimação da dominação, que contribuem para assegurar a dominação de uma classe sobre outra (violência simbólica) dando o reforço da sua própria força às relações de força que as fundamentam contribuindo assim para a submissão inconsciente dos dominados. (BOURDIEU, 1989, p.11).
\end{abstract}

A sociologia de Bourdieu tem o intuito primordial de objetivar e desvendar as imposições simbólicas, revelando a realidade objetiva por detrás das construções arbitrárias que conservam a ordem estabelecida. A destruição deste poder de imposição "supõe a tomada de consciência do arbitrário", a descoberta da realidade objetiva e a desconstrução da crença inculcada entre os dominados (BOURDIEU, 1989, p. 15). Somente a formulação e o triunfo de um discurso heterodoxo contrário ao senso comum legitimado poderiam reverter esse processo e dotar de poder as classes dominadas.

\title{
O Poder (Disciplinar) em Foucault
}

Buscaremos nesta seção apresentar alguns aspectos da concepção acerca do poder presente nos pressupostos teóricos de Michel Foucault (2011), principalmente, relativos à ideia de poder disciplinar conforme explicitada na obra Vigiar e punir.

O poder em Foucault parece possuir um caráter ainda mais fluido, intangível do que nas concepções de Pierre Bourdieu. Em Bourdieu, em certa medida, o poder exige a cumplicidade do outro, como o autor evidencia na violência simbólica, que para ser exercida, precisa do reconhecimento do dominado, isto é, o papel ativo do agente no processo, mesmo para aceitar o poder e a dominação.

Para Foucault, o poder não existe enquanto coisa, ele é um funcionamento, um mecanismo; a partir dos "regimes de verdade" estabelecidos o "poder mais se exerce do que se possui":

O estudo desta microfísica supõe que o poder nela exercido não seja concebido como uma propriedade, mas como uma estratégia, que seus efeitos de dominação não sejam atribuídos a uma 'apropriação', mas a disposições, a manobras, a táticas, a técnicas, a funcionamentos; que se desvende nele antes uma rede de relações sempre tensas, sempre em atividade, que um privilégio que se pudesse deter; que lhe seja dado como 
modelo antes a batalha perpétua que o contrato que faz uma cessão ou a conquista que se apodera de um domínio. (FOUCAULT, 2011, p. 29).

Para o filósofo francês, as relações sociais são sempre relações de poder, pois estas não se localizam apenas entre o Estado e os cidadãos ou na fronteira das diferentes classes sociais, mas se aprofundam dentro da sociedade "ao nível dos indivíduos, dos corpos, dos gestos e dos comportamentos" (FOUCAULT, 2011, p.30).

Foucault (2011) constata, na nascente sociedade burguesa, o deslocamento do centro do poder; antes concentrado na figura do soberano, agora ele se ramifica corporificando-se nas normas e nas novas instituições que surgiam.

Assim, em Vigiar e punir, o autor opera uma genealogia do poder punitivo demonstrando como o deslocamento do objeto da ação punitiva transforma o que antes era uma "arte das sensações insuportáveis" - referência aos suplícios e as execuções públicas -, em uma "economia dos direitos suspensos", relativa ao nascimento e aperfeiçoamento das novas técnicas do poder, quais sejam: a disciplina, a reclusão e a vigilância incessante (FOUCAULT, 2011, p.16, p.21).

$\mathrm{Na}$ formulação de sua teoria sobre as novas formas de controle social, o autor ressalta importância da "minúcia dos regulamentos", do "olhar esmiuçante das inspeções" e do "controle das mínimas parcelas da vida e do corpo" que estarão presentes, de forma cada vez mais radicalizada, na escola, no quartel, no hospital e na fábrica (FOUCAULT, 2011, p. 136).

$\mathrm{Na}$ oficina, na escola, no exército funciona como repressora toda uma micropenalidade do tempo (atrasos, ausências, interrupções das tarefas), da atividade (desatenção, negligência, falta de zelo), da maneira de ser (grosseria, desobediência), dos discursos (tagarelice, insolência), do corpo (atitudes 'incorretas', gestos não conformes, sujeira), da sexualidade (imodéstia indecência). [...] é utilizada, a título de punição, toda uma série de processos sutis, que vão do castigo físico leve a privações ligeiras e a pequenas humilhações. Trata-se ao mesmo tempo de tornar penalizáveis as frações mais tênues da conduta, e de dar uma função punitiva aos elementos aparentemente indiferentes do aparelho disciplinar. (FOUCAULT, 2011, p. 172).

Vemos, portanto, um poder mais discreto, porém, onipresente, que substitui o brilho das manifestações vultosas de poder (os grandes rituais do poder - coroação, submissão dos súditos, ostentação das conquistas), "pelo jogo ininterrupto dos olhares calculados”. O poder disciplinar se exerce "tornando-se invisível: em compensação impõe aos que submete um princípio de visibilidade obrigatória". Pois, na "disciplina, são os súditos que têm que ser vistos" (FOUCAULT, 2011, p. 170; p.179). 
O poder disciplinar - ao invés de diretamente se apropriar e retirar - tem como objetivo maior "adestrar para retirar e se apropriar ainda mais e melhor". Este poder fabrica os indivíduos, tomando-os como objetos e instrumentos do seu exercício. "Não é um poder triunfante", é um poder "modesto", entretanto, "permanente". Seu sucesso deve-se à utilização de instrumentos simples, como o "olhar hierárquico, a sanção normalizadora e o exame" (FOUCAULT, 2011, p. 164).

Organiza-se assim como um poder múltiplo, automático e anônimo; pois, se é verdade que a vigilância repousa sobre os indivíduos, seu funcionamento é de uma rede de relações de alto a baixo, mas também até certo ponto de baixo para cima e lateralmente; essa rede 'sustenta' o conjunto e o perpassa de efeitos de poder que se apóiam uns sobre os outros: fiscais perpetuamente fiscalizados. $\mathrm{O}$ poder na vigilância hierarquizadas das disciplinas não se detém como uma coisa, não se transfere como uma propriedade; funciona como uma máquina. E se é verdade que sua organização piramidal lhe dá um 'chefe', é o aparelho inteiro que produz 'poder' e distribui os indivíduos nesse campo permanente e contínuo. O que permite ao poder disciplinar ser absolutamente indiscreto, pois está em toda a parte e sempre alerta, pois em princípio não deixa nenhuma parte às escuras e controla continuamente os mesmos que estão encarregados de controlar; e absolutamente discreto, pois funciona permanentemente e em grande parte em silêncio. (FOUCAULT, 2011, p.170).

Michel Foucault ressalta que temos de abandonar as concepções referentes ao poder que o encaram sempre em termos negativos (proíbe, reprime, coíbe, censura, impede). Para o autor, o que parece interessar, é o que o poder produz; ele produz indivíduos, produz regimes de verdade, produz, enfim, realidade.

\section{O Poder como Estrutura: Bourdieu e Foucault}

Guardadas as diferenças teóricas e metodológicas entre os autores, podemos aproximar as concepções de poder presentes, tanto no pensamento de Foucault, quanto no de Bourdieu - assim como nos afastar das proposições clássicas e hegemônicas de Weber através da noção de estrutura.

Concebemos estrutura como "um conjunto de interações sociais padronizadas, regulares e que duram no tempo", elas seriam o resultado de "processos históricos marcados pela concorrência de ações estratégicas entre diversos atores" (PERISSINOTTO, 2007, p.314).

Para Bourdieu e Foucault o poder deve ser entendido como uma estrutura de relações que distribui os indivíduos em posições hierarquizadas definindo acessos desiguais a recursos 
sociais estratégicos. A estrutura é envolvida por uma luta simbólica que faz com que ela se apresente aos atores sociais - tanto dominados, quanto dominantes - como natural (PERISSINOTTO, 2007).

Essa estrutura é o poder, e o poder, assim compreendido, é um fenômeno duradouro e invisível, difícil de ser apreendido. A realidade imediata ocultaria as lutas passadas - seus vencidos e vencedores - apresentando-se aos indivíduos como óbvia e imutável. A relação de dominação, portanto, não é percebida e os dominados aderem aos valores dominantes, tidos como legítimos, como se estes fossem os únicos possíveis.

O tipo de poder que observamos a partir dessa perspectiva não produz ameaças, mas o convencimento e a submissão simbólica ao estado atual das coisas. Bourdieu e Foucault desvendam um poder que age de maneira sutil e cotidiana, moldando sistematicamente os desejos, as escolhas e as ações dos atores envolvidos.

O que Foucault e Bourdieu têm em comum é, por assim dizer, uma desconfiança em relação ao consenso que caracteriza as relações sociais presentes. Essa desconfiança estaria autorizada por uma percepção inicial acerca das desigualdades que caracterizam a distribuição de recursos sociais. [...] Para os dois autores, essa percepção inicial de que a sociedade se estrutura com base numa distribuição desigual de recursos, que, por sua vez, produz desigualdades estruturais quanto à capacidade de ação dos atores sociais, torna legítimo supor que a continuidade dessa situação se deva a mecanismos de poder que 'convencem' os dominados a aceitarem a sua posição inferior no sistema de diferenciações ou nas relações de força que caracterizam o campo. Ou por outra, seria lícito supor que os dominados gostariam de reverter a sua posição caso tivessem consciência dela. (PERISSINOTO, 2007, p. 317).

O poder - simbólico e disciplinar - é proveniente de “[...] eficientes processos de socialização geradores, no caso de Foucault, de almas disciplinadas e, no caso de Bourdieu, de agentes portadores de um habitus adequado à sua posição social.” (PERISSINOTO, 2007, p. 318).

\section{Considerações finais}

Nosso intuito foi o de apresentar aquilo que consideramos como as proposições fundamentais que caracterizam a singularidade das formulações acerca do poder presentes no pensamento de Pierre Bourdieu e Michel Foucault. Como forma de ressaltar esta singularidade, optamos por expor, também, os fundamentos da concepção hegemônica sobre o poder, centrada em Max Weber. 
Reconhecendo que a teoria weberiana sobre o poder e a dominação é muito mais rica e complexa, nosso exercício foi operar uma comparação entre os pressupostos básicos das definições de poder em Weber, cujo traço essencial é de intencionalidade e de cálculo racional por parte dos agentes envolvidos. Por outro lado, em Bourdieu e Foucault o poder é entendido como algo abstrato, não localizável, que existe enquanto relação, moldando a mente e os corpos de sujeitos que nem sequer se dão conta de que são tocados e influenciados por uma força exterior.

\section{REFERÊNCIAS}

BOURDIEU, P. A economia das trocas simbólicas. 6.ed. São Paulo: Perspectiva, 2007. BOURDIEU, P. A distinção: crítica social do julgamento. Porto Alegre: Zouk, 2006. BOURDIEU, P. A dominação masculina. 2.ed. Rio de janeiro: Bertrand Brasil, 2002. BOURDIEU, P. O poder simbólico. Rio de Janeiro: Bertrand Brasil, 1989.

BOURDIEU, P.; PASSERON, J.-C. Os herdeiros: os estudantes e a cultura. Florianópolis: Editora da UFSC, 2014.

FOUCAULT, M. Vigiar e punir: nascimento da prisão. 39.ed. Petrópolis, RJ: Vozes, 2011. PERISSINOTTO, R. História, sociologia e análise do poder. Revista História Unisinos, Rio Grande do Sul, v. 11, n. 3, p.313-320, 2007.

WACQUANT, L. Poder simbólico e fabricação de grupos: como Bourdieu reformula a questão das classes. Novos Estudos-CEBRAP, São Paulo, n. 96, p. 87-103, 2013.

WEBER, M. Economia y sociedad. México: Fondo de Cultura Económica, 1984.

\section{Como referenciar este artigo}

ROSA, Tiago Barros. O poder em Bourdieu e Foucault: considerações sobre o poder simbólico e o poder disciplinar. Rev. Sem Aspas, Araraquara, v.6, n.1, p. 3-12, jan./jun. 2017. e-ISSN 2358-4238.

Submetido em: 31/05/2017

Aprovado em: 30/06/2017 